\title{
Description of a new Pselaphodes Westwood (Coleoptera: Staphylinidae: Pselaphinae) from Vietnam
}

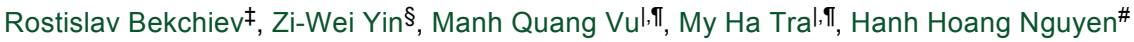 \\ ‡ National Museum of Natural History, Bulgarian Academy of Sciences, 1 Tsar Osvoboditel Blvd., 1000, Sofia, Bulgaria \\ $\S$ Lab of Environmental Entomology, College of Life Sciences, Shanghai Normal University, 100 Guilin Road, Shanghai 200234, \\ Shanghai, China \\ | Hanoi National University of Education (HNUE), 136 Xuan Thuy Rd., DHSP Cau Giay, Hanoi, Vietnam \\ If Ho Chi Minh City University of Food Industry, 140 Le Trong Tan St., Tan Phu, Ho Chi Minh, Vietnam \\ \# Institute of Ecology and Works protection, Hanoi, Vietnam
}

Corresponding author: Rostislav Bekchiev (bekchiev@nmnhs.com)

Academic editor: Stylianos Chatzimanolis

Received: 05 Sep 2019 | Accepted: 27 Sep 2019 | Published: 03 Oct 2019

Citation: Bekchiev R, Yin Z-W, Quang Vu M, Tra MH, Nguyen HH (2019) Description of a new Pselaphodes

Westwood (Coleoptera: Staphylinidae: Pselaphinae) from Vietnam. Biodiversity Data Journal 7: e46327.

https://doi.org/10.3897/BDJ.7.e46327

ZooBank: urn:Isid:zoobank.org:pub:7C0134C1-47E0-419A-837E-A3BE1BE2B233

\section{Abstract}

\section{Background}

A new species of the genus Pselaphodes Westwood, P. fansipanensis Bekchiev \& Yin sp. $\mathrm{n}$., is described from northern Vietnam. The unique modification of the antennomeres 9-10 of the male readily separates the new species from all known congeners.

\section{New information}

New Pselaphodes species from Vietnam 


\section{Keywords}

Asia, Indochina, Tyrini, taxonomy, new species

\section{Introduction}

The Pselaphinae (Coleoptera: Staphylinidae) fauna of Vietnam is poorly studied. Until now, 112 species (Bekchiev 2010, Nomura 2013, Nomura and Pham 2019) have been known from the country. The diversity of habitats and environmental conditions in Vietnam implies that the diversity of pselaphine fauna may be much greater. A total of 65 species of Pselaphodes (Tyrini) have been described, all from the Oriental region - China, Nepal, India, Sri Lanka, Thailand, the Philippines and East Malaysia (see Huang et al. 2018 for checklist and distributional map) and two additional unnamed species were recently reported from Vietnam (Nomura and Pham 2019).

In September 2018, a short expedition to southern and northern Vietnam was organised by the Institute of Ecology and Works Protection (Hanoi) and the National Museum of Natural History (Sofia), giving the opportunity to collect rich zoological material. One of the visited localities was Fansipan Mountain and, especially, the Fansipan Summit. It is the highest $(3,143$ metres a.s.I.) mountain in the Indochinese Peninsula (including Vietnam, Laos and Cambodia), hence its nickname "the Roof of Indochina".

Included in the material was a new Pselaphodes species, which is described below.

\section{Materials and methods}

The material was collected in an open habitat with shrubs and grasses (Fig. 1) by soil and litter sifting.

Specimens were examined by Zeiss Stemi 2000C stereo-microscopes. Male genitalia and other dissected parts were studied using a Zeiss transmitted-light microscope at magnifications up to 500x. Genital segments were dissected and treated with potassium hydroxide $(\mathrm{KOH})$. The dissected parts were mounted in Euparal and pinned with the relevant specimen.

The following acronyms are used in the text: $\mathrm{BL}$-length of the body $(=\mathrm{HL}+\mathrm{PL}+\mathrm{EL}+$ $\mathrm{AL})$; $\mathrm{HL}$-length of the head from the anterior clypeal margin to the occipital constriction; $\mathrm{HW}$ - width of the head across eyes; $\mathrm{PL}$ - length of the pronotum along the midline; $\mathrm{PW}-$ maximum width of the pronotum; EL-length of the elytra along the suture; EW-maximum width of the elytra; $A L$-length of dorsally visible part of the abdomen along the midline; AW_-maximum width of the abdomen; NMNHS - National Museum of Natural History, Sofia, Bulgaria 


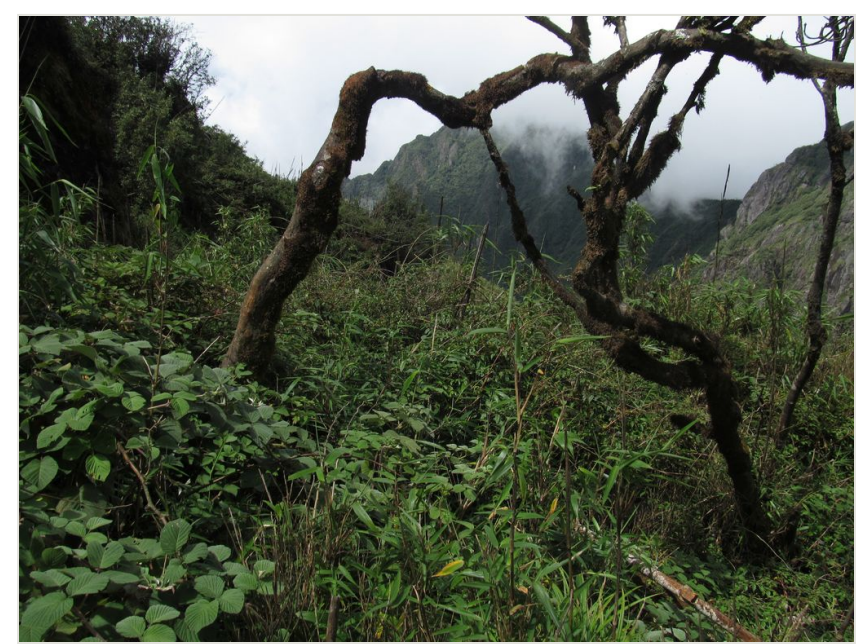

Figure 1. doi

Fansipan Summit - habitat of Pselaphodes fansipanensis sp. n.

The type specimen is provided with a red printed label: "HOLOTYPUS", "Pselaphodes fansipanensis sp. n.", "R. Bekchiev \& Zi-Wei Yin, 2019 “.

\section{Taxon treatment}

\section{Pselaphodes fansipanensis Bekchiev \& Yin, sp. n.}

- ZooBank urn:Isid:zoobank.org:act:EB4A1A24-6782-4926-97E6-08CCFF8B1B79

\section{Material}

\section{Holotype:}

a. $\quad$ scientificNameID: Pselaphodes fansipanensis; higherClassification: Coleoptera; Staphylinidae; Pselaphinae; class: Insecta; order: Coleoptera; family: Staphylinidae; taxonRank: species; genus: Pselaphodes; specificEpithet: fansipanensis; locationID: Fansipan peak; higherGeographyID: Lao Cai Province; higherGeography: Vietnam; continent: Asia; verbatimElevation: 2992 m; verbatimLatitude: 22.30560; verbatimLongitude: 103.77625; decimalLatitude: 22.30560; decimalLongitude: 103.77625; individualCount: 1; sex: male; lifeStage: adult; recordedBy: R. Bekchiev, N. Simov, I. Dedov, P. Beron; identifiedBy: Rostislav Bekchiev, Zi-Wei Yin; dateldentified: 2019; institutionID: National Museum of Natural History-Sofia; institutionCode: NMNHS

\section{Description}

Male (Fig. 2). Body reddish-brown, covered with short golden setae, BL $3.14 \mathrm{~mm}$. Head slightly longer than wide, HL $0.62 \mathrm{~mm}$, HW $0.56 \mathrm{~mm}$; each eye composed of about 40 facets. 


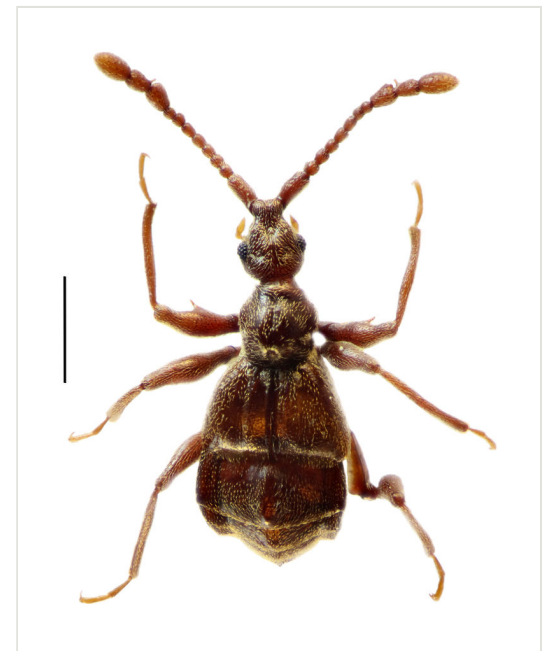

Figure 2. doi

Pselaphodes fansipanensis sp. n. - habitus. Scale bar: $1.0 \mathrm{~mm}$.

Antennomeres (Fig. 3a) 9-11 forming distinct club, antennomere 9 modified, with discshaped process at apex, antennomere 10 with thin, elongate protuberance at base. Pronotum as long as wide, PL $0.62 \mathrm{~mm}$, PW $0.63 \mathrm{~mm}$, coarsely punctate and regularly pubescent, with lateral margins rounded at apical third and then narrowing apicad. Elytra wider than long, EL $0.78 \mathrm{~mm}$, EW $1.18 \mathrm{~mm}$. Metaventral processes short, triangular, curved ventrally at apices in lateral view. Protrochanter with one thin projection, profemur (Fig. 3b) with one large, bluntly triangular ventral projection; protibia simple; mesotrochanter with two ventral spines, one minute and one larger, one minute and one distinct ventral spines (Fig. 3c); mesofemur and mesotibia simple; hind legs simple. Abdomen broad at base and narrowed apically, with large hump at middle of tergite IV; AL $1.12 \mathrm{~mm}$, AW $1.24 \mathrm{~mm}$.

Length of aedeagus $0.77 \mathrm{~mm}$, median lobe broad and asymmetrical, parameres elongate, endophallus with one elongate sclerite (Fig. $3 d$, e); the apical part of the median lobe was broken and lost during the preparation of the specimen.

Female. Unknown.

\section{Etymology}

The new species is named after Fansipan Summit, the type locality of the new species.

\section{Distribution}

North Vietnam: Lao Cai Province. 


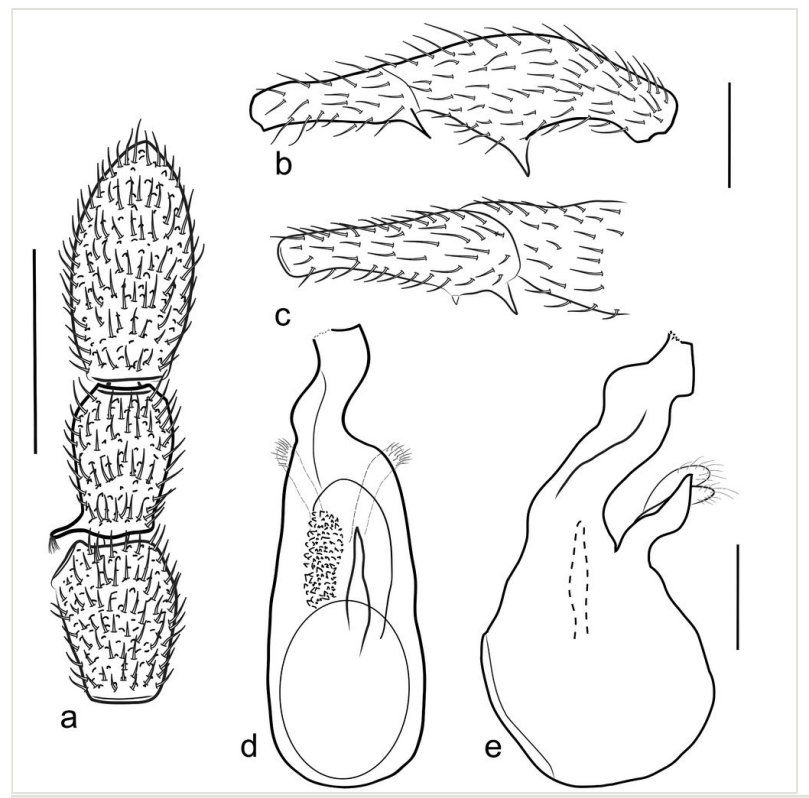

Figure 3. doi

Pselaphodes fansipanensis sp. n. - a) antennal club; b) protrochanter and profemur; c) mesotrochanter; $d, e)$ aedeagus - dorsal and lateral view. Scale bar: $0.2 \mathrm{~mm}$.

\section{Taxon discussion}

The new species can be readily separated from all other members of the genus by the unique modification of the antennomeres 9-10 and the short, triangular metaventral processes of the male, as well as the shape of the aedeagus.

\section{Acknowledgements}

The research was supported by projects "Research on ecologically sustainable development model on the coastal area of Mekong Delta"-Code Number: 10/2017/ HĐ.ĐTĐL.CN.CNN; Research on model construction of biodiversity conservation in village scale in Mui Ca Mau biosphere reserve"; Code number: ĐTĐL.CN-26/17.

\section{References}

- Bekchiev R (2010) Description of the second species of the genus Taiwanophodes Hlaváč, 2002 (Coleoptera: Staphylinidae: Pselaphinae) from Vietnam. Russian Entomological Journal 19 (3): 183-185. https://doi.org/10.15298/rusentj.19.3.05

- Huang M, Li L, Yin Z (2018) Eleven new species and a new country record of Pselaphodes (Coleoptera: Staphylinidae: Pselaphinae) from China, with a revised checklist of world 
species. Acta Entomologica Musei Nationalis Pragae 58 (2): 457-478. https:// doi.org/10.2478/aemnp-2018-0035

- $\quad$ Nomura S (2013) A checklist of the Pselaphine species (Coleoptera, Staphylinidae) of Vietnam. Japanese Journal of Systematic Entomology 19 (2): 233-242.

- $\quad$ Nomura S, Pham TH (2019) List of Pselaphine species (Insecta, Coleoptera, Staphylinidae) collected by light traps from North Vietnam in 2014 with supplements and corrections to the check-list of Nomura (2013). Bulletin of the National Science Museum (A: Zoology) 45 (2): 73-83. 